\title{
Phylogenetic analysis and molecular characteristics of seven variant Chinese field isolates of PRRSV
}

Chengmin Wang ${ }^{1}$, Bin Wu ${ }^{1,2}$, Said Amer ${ }^{1,4}$, Jing Luo ${ }^{1}$, Hongmei Zhang ${ }^{3}$, Yunhai Guo ${ }^{1}$, Guoying Dong ${ }^{1}$, Baohua Zhao ${ }^{2}$, Hongxuan $\mathrm{He}^{\text {1* }^{*}}$

\begin{abstract}
Background: Porcine reproductive and respiratory syndrome (PRRS) has now been widely recognized as an economically important disease. The objective of this study was to compare the molecular and biological characteristics of porcine reproductive and respiratory syndrome virus (PRRSV) field isolates in China to those of the modified live virus (MLV) PRRS vaccine and its parent strain (ATCC VR2332).

Results: Five genes (GP2, GP3, GP4, GP5 and NSP2) of seven isolates of PRRSV from China, designated LS-4, HM-1, HQ-5, HQ-6, GC-2, GCH-3 and ST-7/2008, were sequenced and analyzed. Phylogenetic analyses based on the nucleotide sequence of the ORF2-5 and NSP2 showed that the seven Chinese isolates belonged to the same genetic subgroup and were related to the North American PRRSV genotype. Comparative analysis with the relevant sequences of another Chinese isolate (BJ-4) and North American (VR2332 and MLV) viruses revealed that these isolates have 80.8-92.9\% homology with VR-2332, and 81.3-98.8\% identity with MLV and 80.7-92.9\% with BJ-4. All Nsp2 nonstructural protein of these seven isolates exhibited variations (a 29 amino acids deletion) in comparison with other North American PRRSV isolates. Therefore, these isolates were novel strain with unique amino acid composition. However, they all share more than $97 \%$ identity with other highly pathogenic Chinese PRRSV strains. Additionally, there are extensive amino acid (aa) mutations in the GP5 protein and the Nsp2 protein when compared with the previous isolates.
\end{abstract}

Conclusions: These results might be useful to study the genetic diversity of PRRSV in China and to track the infection sources as well as for vaccines development.

\section{Background}

Porcine reproductive and respiratory syndrome virus (PRRSV) is recognized as one of the major infective agents in the pig industry worldwide since its appearance in the 1980s. It was first diagnosed in the USA in 1987 [1], immediately found in Europe, soon disseminated to the rest of the world [2]. The disease is characterized by reproductive failure in pregnant sows and respiratory distress particularly in suckling piglets, thereupon getting its name. PRRSV is a single-stranded positive RNA virus and a member of the family Arteriviridae in the order of Nidovirales [3]. Based on phylogenetic analyses of

\footnotetext{
* Correspondence: hehx@ioz.ac.cn

${ }^{1}$ National Research Center for Wildlife Born Diseases, Institute of Zoology, Chinese Academy of Sciences, Beijing 100101, China
}

different virus isolates around the world, PRRSV can be differentiated into two genotypes: Type I, represented by the European prototype Lelystad strain LV, and Type II, the prototype being the Northern American ATCC strain VR2332. Chinese isolates were assigned as members of the genotype II [4]. Extensive molecular studies show that PRRSV is highly variable in antigenicity, virulence and sequence diversity $[5,6]$.

PRRSV is a small, enveloped, single positive-stranded RNA virus including a genome of about $15 \mathrm{~kb}$, encoding nine ORFs $[2,7,8]$. The PRRSV genome is comprised of two polymerase genes, ORF1a and $1 \mathrm{~b}$, and seven structural genes, ORF2a, 2b, 3, 4, 5, 6, and 7 [9]. ORF1a and ORF1b constitutes approximately $75 \%$ of the viral genome, and are characterized by a process of ribosomal frame shifting translated into a large polyprotein; which 
by self-cleavage gives rise to the non-structural proteins (NSPs) including the RNA-dependent RNA polymerase [10]. Open reading frames $2 \mathrm{a}, 3,4$ and 5 all encode glycosylated proteins, designated GP2a, GP3, GP4, and GP5, respectively $[7,11]$. The newly defined ORF2b encodes the smallest protein of the virus particle designated GP2b $[8,12]$. ORF7 encodes the non-glycosylated nucleocapsid protein $(\mathrm{N})$, constituting $20-40 \%$ of the protein content of the virion $[8,13,14]$. ORF6 encodes the likewise non-glycosylated matrix protein $(\mathrm{M})[8,12]$. Heterodimers constituted by GP5 and M have been found in the endoplasmic reticulum of infected cells [14], and have been suggested to be involved in virushost cell receptor interaction [15]. A rapid genetic divergence of PRRSV was revealed by an experiment of serial in vivo passage of a PRRSV strain [16] and by an analysis of naturally infected pigs. The presence of genetically divergent viruses in a swine population may complicate the disease control by vaccination, because the PRRSV vaccine efficacy is reduced when the challenge virus is a virus of a different genotype [17] or of a different phylogenetic cluster within the same genotype [18].

In China the first outbreak of PRRS was recorded in 1995 which encountered almost all provinces (include Hong Kong). Due to its economic impact in China, the disease has been recognized as one of the most severe viral diseases for pig farms. The first Chinese strain of PRRSV was isolated in 1996, and the complete genome sequence of the Chinese PRRSV isolate BJ-4 was first reported in 2001 [19]. Highly pathogenic PRRSV is the causative agent of porcine high fever syndrome and characterized by high fever and high death rates in pigs of all ages. Since May 2006, the highly pathogenic PRRSV has emerged in China. Recently, the genomic characteristics of two other Chinese isolates of PRRSV were described with comparisons to some American and European isolates [4]. It has been documented that PRRSV strains differ in virulence [20-23] and vary genetically $[24,25]$. Concerns that vaccine strains or derivatives of the vaccine strains may induce disease continue to be discussed [26-28]. The objective of this research was to compare the genetic and molecular characteristics of seven Chinese PRRSV field isolates to that of a known high-virulence PRRSV isolate (BJ-4), the Ingelvac PRRS MLV vaccine, and the parent strain of the vaccine (ATCC VR2332). The results inferred from this study might be useful for infection tracking as well as for vaccines development.

\section{Results and discussion}

For a long time, outbreaks of highly pathogenic (acute, atypical) PRRS in many Chinese territories have been attributed to the highly virulent Chinese-type PRRSV (H-PRRSV) strains. From January to July 2007, 39455 morbid pigs died among 143,221 infected pigs according to the administrative files [29]. New types of PRRSV variants with high pathogenicity were identified in China was responsible for severe impact on pig industry as well as food safety [30]. Concurrently, this Chinese variant of PRRSV was detected in Vietnam where it caused a serious epidemic [31].

In this study, LS-4, HM-1, HQ-5, GCH-3, GC-2, HQ-6 and ST-7 strains were isolated from Hebei province. Homology search and phylogenetic analyses indicated that the sequences of seven isolates belong to the American (AM) genotype (Figure 1). Two subgroups were classified based on ORF2, ORF3, ORF4, ORF5 and NSP2 genes of Chinese American genotype isolates, and named as subgroup AM-I and AM-II (Figure 1). These seven isolates clustered to the subgroup AM-I for ORF2-5 and NSP2, whereas the Chinese isolates BJ-4, VR2332 and MLV were affiliated with subgroup AM-II based on ORF2-4 and NSP2. MLV joined the seven isolates into the subgroup (AM-I) based on ORF5 genes and show a higher evolutionary divergence (2.372-2.429) at the nucleotide acid level (Additional file 1). The results have indicated that all seven Chinese virus isolates formed a subgroup in the North American genotype, but the BJ-4 isolate was assigned to another subgroup closely related to the vaccine strain RespPRRS/ Repro, suggesting that these strains may not be evolved from a revertant of the vaccine virus.

The glycoprotein 2 (gp2) is a minor component of the PRRSV envelope [32] with 2 B-cell linear epitopes, whose reactive peptides comprise regions at amino acid positions 41-55 and 121-135 within the ORF2 sequence [33]. In the present study, those seven Chinese isolates have a lower evolutionary divergence (0.086-0.107) with VR-2332, and (0.077-0.098) with MLV and BJ-4 for ORF2 (Additional file 2). In comparison to VR2332 and MLV, two AA mutations were found at positions 42 $(\mathrm{P} \rightarrow \mathrm{Q} / \mathrm{R})$ and $50(\mathrm{~F} \rightarrow \mathrm{Y})$ (Figure $2 \mathrm{~A})$ and have influenced the hydrophobicity of the reactive peptides 41-55 (Figure 2B). However, another mutation at AA position $122(\mathrm{~S} \rightarrow \mathrm{A})$ did not affect the hydrophobicity of the reactive peptides 121-135 (Figure $2 \mathrm{~B}$ ). In addition, other AA mutations such as positions $23(\mathrm{~S} \rightarrow \mathrm{N}), 24(\mathrm{~S} \rightarrow \mathrm{F}), 91$ $(\mathrm{T} \rightarrow \mathrm{K})$ and $97(\mathrm{M} \rightarrow \mathrm{V})$ affect obviously the hydrophobicity of gp2 protein, which might alter the antigenic activity of gp2 (Additional file 3).

The highly glycosylated ORF3-encoded protein is the second most variable PRRSV protein [7], showing approximately an evolutionary divergence of 0.144-0.157 with VR-2332, MLV and BJ-4 (Additional file 4). Marcelo et al (2006) reported that 4 overlapping consecutive peptides (AA positions 61-105) were strongly immunoreactive with $85-100 \%$ of the tested sera. Those peptides were predicted to be located in the most hydrophilic region 


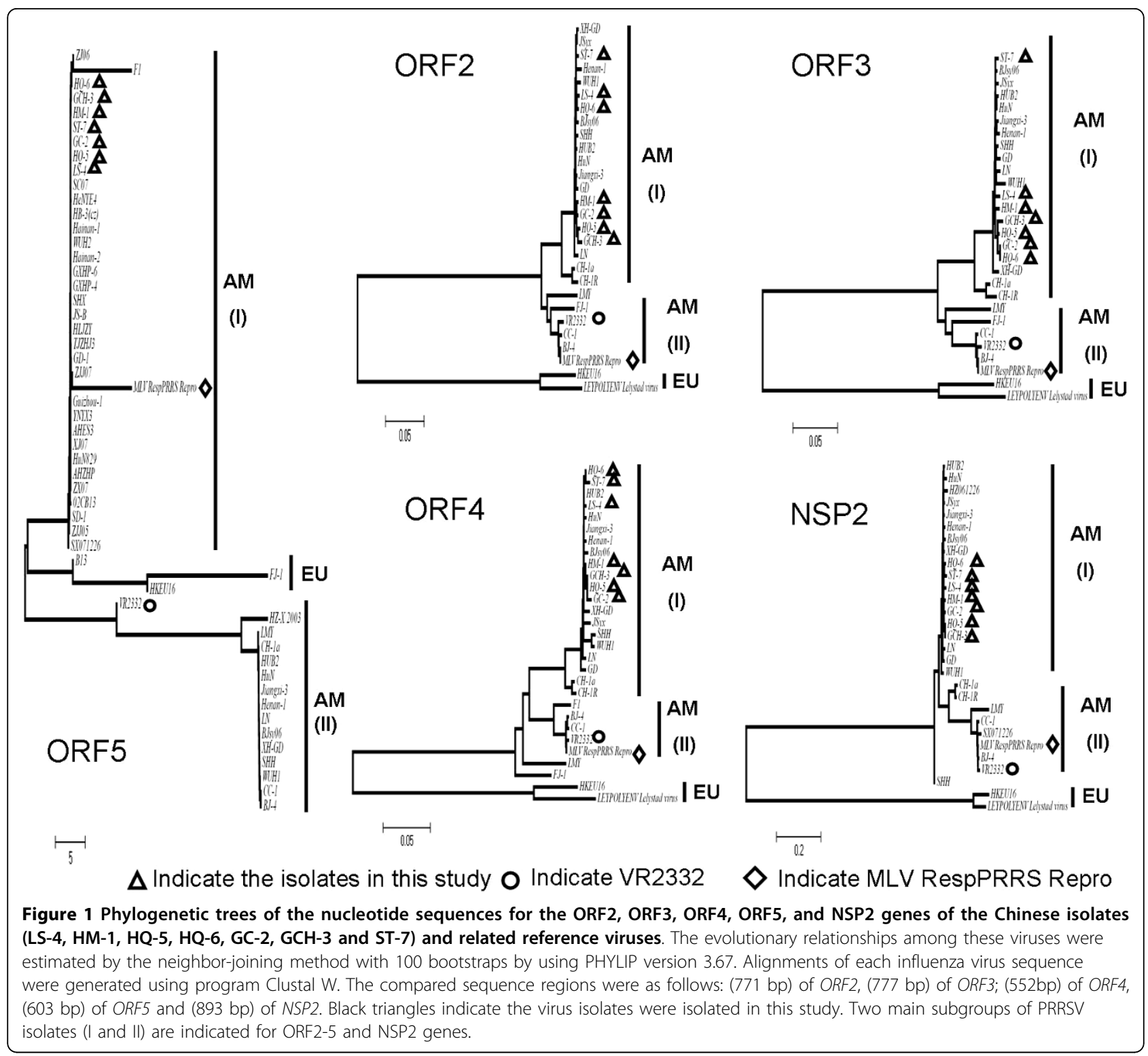

within the ORF3 sequence. Marcelo et al suggested that this region might be considered as an important immuno-dominant domain of the gp3 of North American strains of PRRSV [30]. In this study, eight AA mutations were detected at position 64 to 85 within four overlapping consecutive peptides (Figure 3A). Additionally, two novel epitopes located at 73-87aa (named GP3EP3) and 66-81aa (named GP3EP7) were identified in the gp3 of Chinese isolate (US-type) of PRRSV [34]. These authors found that the minimum amino acid sequence requirements for epitope binding were 74-85aa $\left(\mathrm{W}^{74}\right.$ CRIGHDRCGED ${ }^{85}$ ) and 67-74aa $\left(\mathrm{Y}^{67}\right.$ EPGRSLW $^{74}$ ) using mutation deletion analysis. Especially these mutations at AA positions $64(\mathrm{~T} \rightarrow \mathrm{A}), 67(\mathrm{Y} \rightarrow \mathrm{L}), 71(\mathrm{R} \rightarrow \mathrm{K})$, $73(\mathrm{~L} \rightarrow \mathrm{F}), 79(\mathrm{Y} \rightarrow \mathrm{H}), 83(\mathrm{E} \rightarrow \mathrm{S} / \mathrm{G})$ and $85(\mathrm{D} \rightarrow \mathrm{N})$ affect obviously the hydrophobicity of gp3 protein comparing to VR2332 and MLV (Figure 3B). Furthermore, antigenic index analysis was predicted to observe the changes of antigenic characterization by DNAstar program (DNAStar Lasergene V7.10). The changes of the antigenic index were found to be at AA positions 60-90 (Additional file 5). Additional substitutions were observed at AA positions 1 to 10,130 to 150 and 205-230, where AA mutations at these regions occurred correspondingly (Additional file 5). However, further investigations are needed to determine the effects of such mutations on the host-virus interaction.

The glycoprotein 4 (gp4) is also a minor component of the PRRSV envelope [7] and a typical class I membrane protein [10]. Sequences of ORF4derived from the 


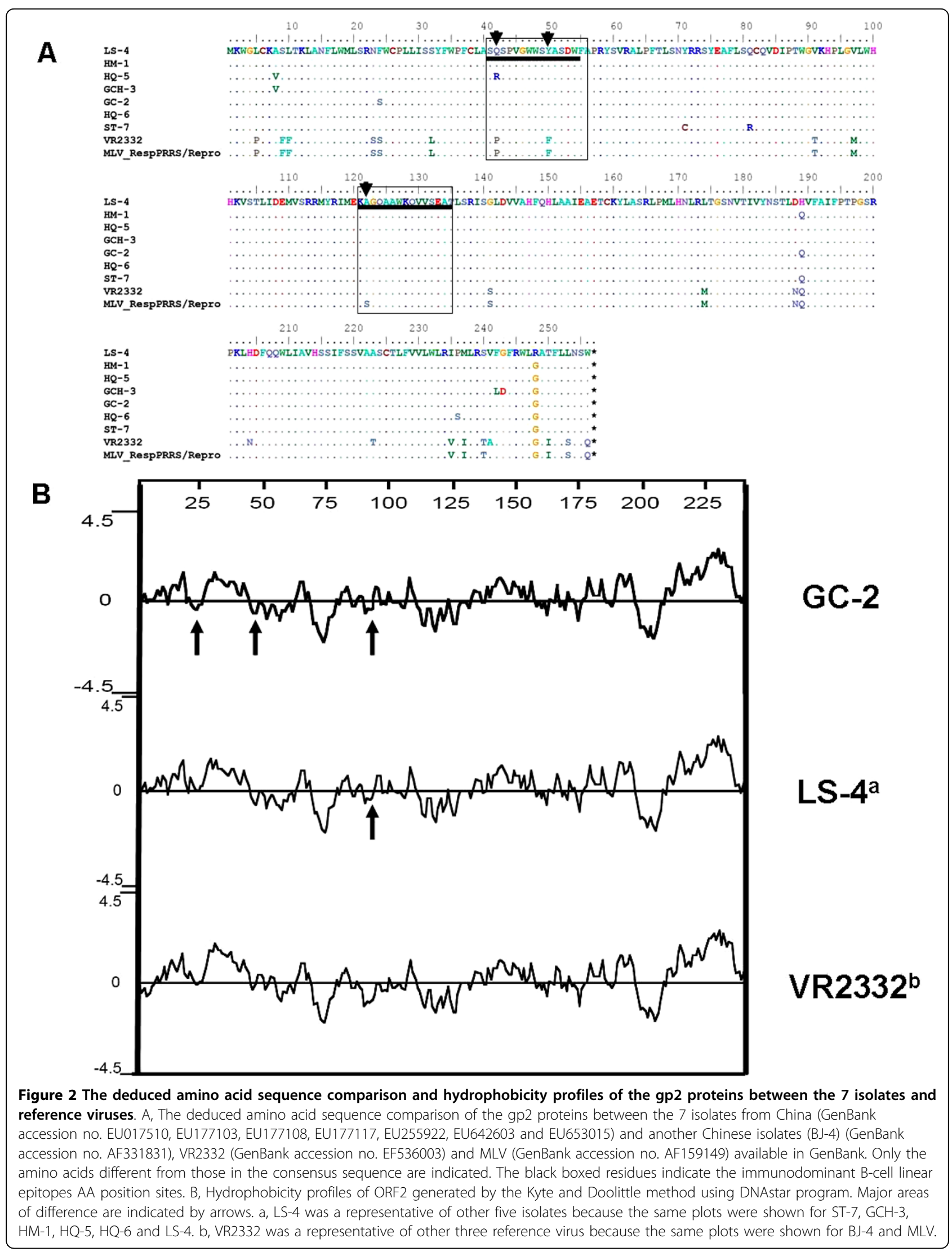




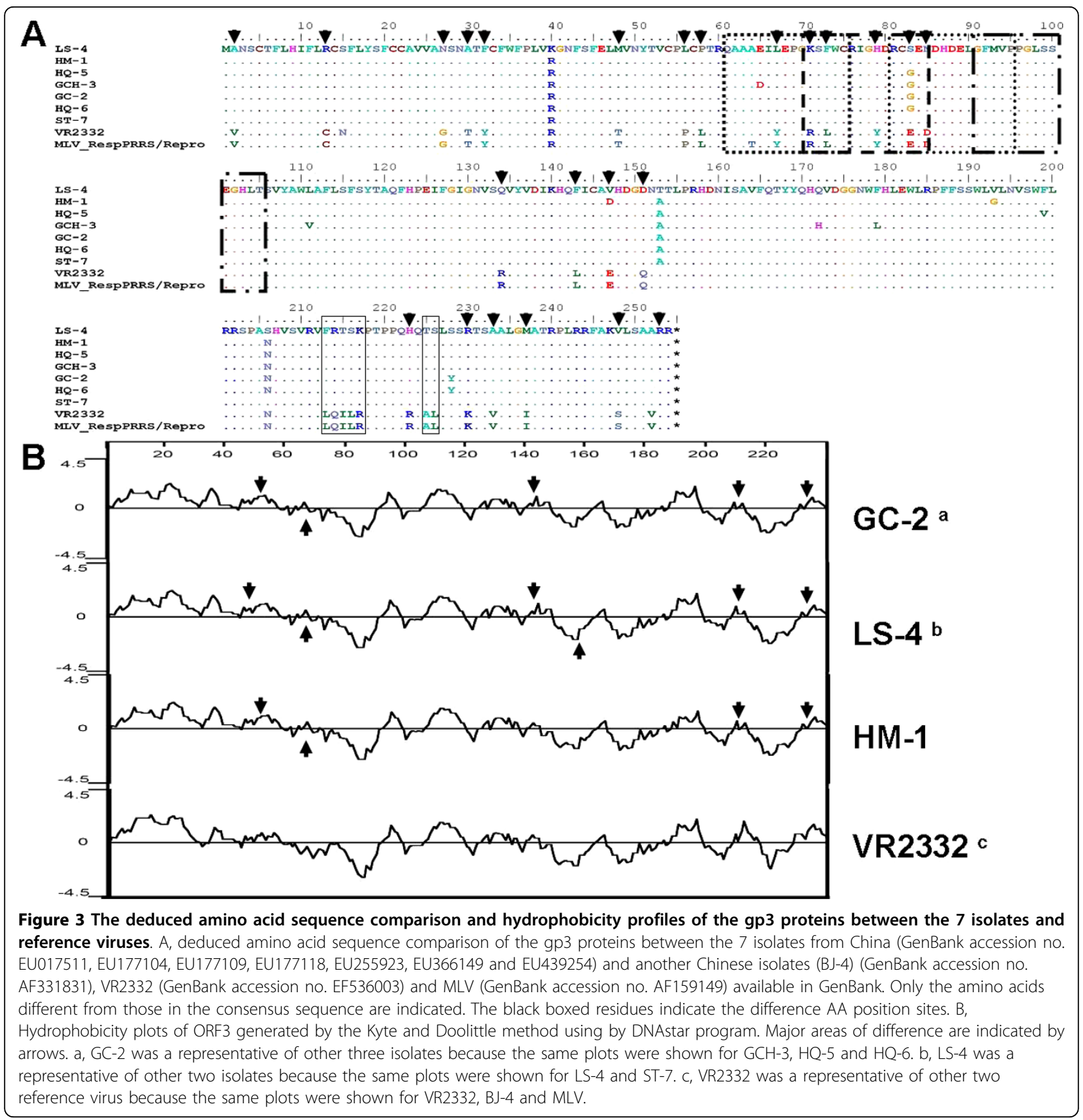

tested seven isolates showed an evolutionary divergence of 0.095-0.108 with VR2332, MLV and 0.102-0.114 with BJ-4 (Additional file 6). Previous study revealed that the gp4 protein of a North American strain of PRRSV contained one immunodominant domain, comprising amino acid residues 51-65 [33]. In our study, those mutations at AA positions $9(\mathrm{~V} \rightarrow \mathrm{L}), 32(\mathrm{~A} \rightarrow \mathrm{S}), 56(\mathrm{R} \rightarrow \mathrm{G}), 59$ $(\mathrm{A} \rightarrow \mathrm{S}), 61(\mathrm{E} \rightarrow \mathrm{P})$ and $78(\mathrm{~V} \rightarrow \mathrm{I})$ obviously affect the hydrophobicity of gp4 protein compared to VR2332 and MLV (Figure 4). The core of a neutralization domain of the glycoprotein encoded by ORF4 of Lelystad virus and recognized by MAbs consists of amino acids 59 to 67 and is located at the most variable region of the protein [35]. The two mutations of positions $59(\mathrm{~A} \rightarrow \mathrm{S})$ and 61 $(\mathrm{E} \rightarrow \mathrm{P})$ exactly located within this region and may affect the antigenicity of Chinese isolates in the present study. Antigenic index analysis revealed that seven antigenic changes for virus isolate LS-4, GCH-3, HM-1, HQ-5, HQ-6 and ST-7 and five antigenic changes for virus isolate GC-2 were observed (Additional file 7). However, 


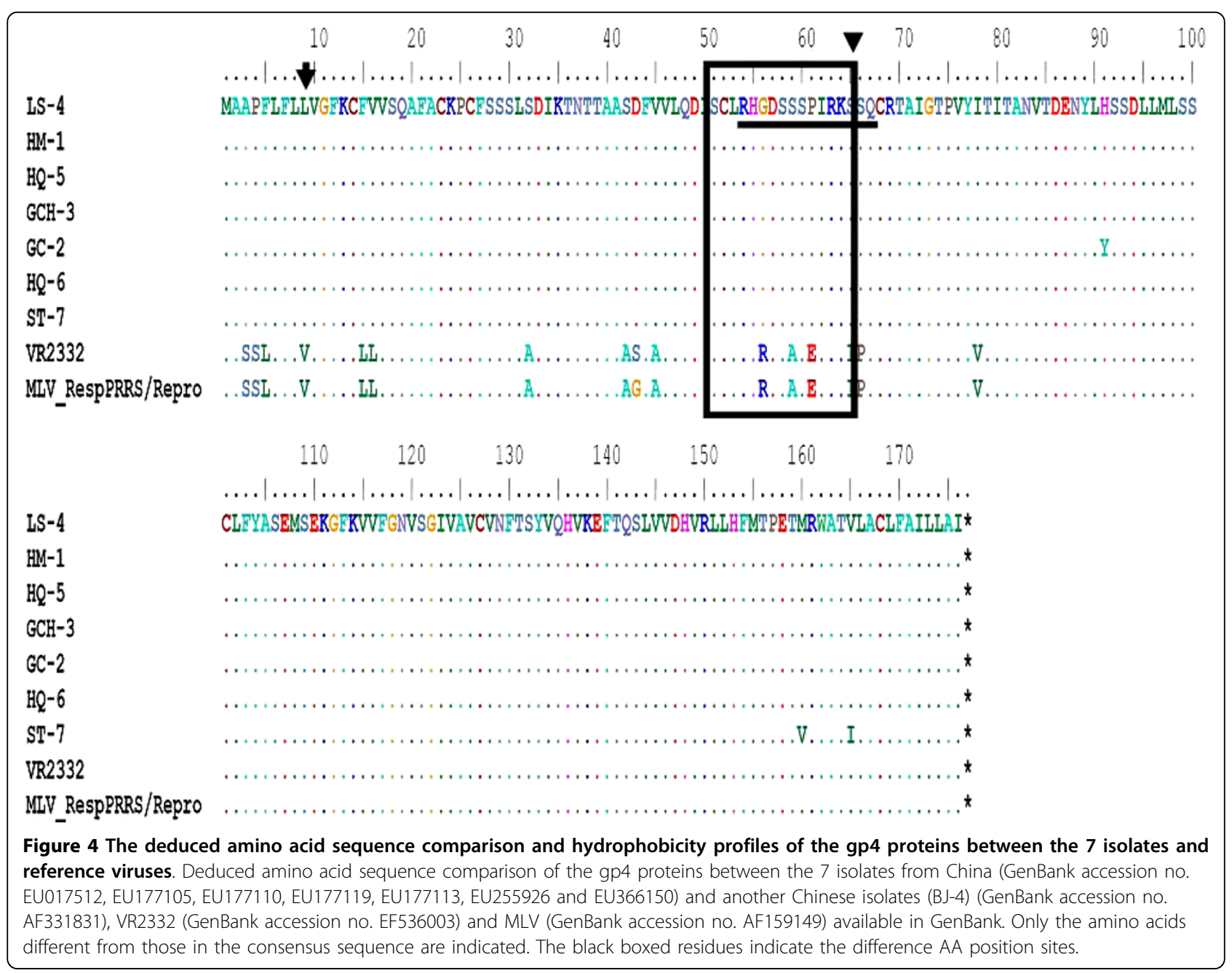

further studies are necessary to demonstrate whether the putative linear epitope identified in the present study is recognized by neutralizing antibodies.

Glycoprotein 5 (gp5) is one of the major structural proteins encoded by PRRSV and forms disulfide-linked heterodimers with $M$ protein in the viral envelope [7]. The ORF5 of PRRSV encodes a 24.5-26 kDa envelope protein with a characteristic hydropathy profile and putative glycosylation sites $[11,14,36]$. Amplicons of ORF5 genes derived from the 7 tested isolates had the same size of $603 \mathrm{bp}$ (deduced amino acids are 201). The sequence alignments indicated that they had an identity of $99-100 \%$ at the nucleotide level and $98-100 \%$ at the amino acid level between MLV and BJ-4. However, the deduced amino acid sequence comparison indicated that those isolates show an higher evolutionary divergence of 2.372-2.429 with VR-2332 and MLV,3.314-3.471 with BJ-4 (Additional file 1), and displayed considerable genetic variation.

Porcine reproductive and respiratory syndrome virus (PRRSV) glycoprotein 5 (GP5) is the most abundant envelope glycoprotein and a major inducer of neutralizing antibodies in vivo, containing three putative $\mathrm{N}$-linked glycosylation sites (N34, N44, and N51), where a major neutralization epitope [37] is located. Plagemann et al. [38] also used peptide mapping to show that the major neutralization epitope of PRRSV is located to the middle of the GP5 ectodomain (aa 36-52). This neutralization epitope is flanked by multiple $\mathrm{N}$-linked glycosylation sites, which are probably important for correct folding, targeting, and biological activity of the protein. The loss of these N-linked glycosylation sites enhances both the sensitivity of these viruses to in vitro neutralization and the immunogenicity of the nearby neutralization epitope. In this study, only gp 5 proteins of isolate LS-4 and HQ-5 had these three $\mathrm{N}$-linked glycosylation sites, while other five isolates (GCH-3, HM-1, HQ-6, GC-2 and ST-7) had two N-linked glycosylation sites (N34 and N51) because of mutation of $\mathrm{N} 44$ glycosylation site $(\mathrm{N} \rightarrow \mathrm{K})$. It has been demonstrated that the retention of N44 was very crucial for infection of PRRSV $[37,39]$. However, the biological 
characterization of those N44 deletion isolates should be further analyzed in future work. These results have indicated the sensitivity of most Chinese virus isolates to neutralization by PRRSV-specific antibodies after vaccination. In another study, a neutralizing epitope in the ectodomain of gp5 has been previously described [40]. The core sequence of this neutralizing epitope (H38, Q40, I42, Y43 and N44) was present in gp5 proteins of isolates LS-4 and HQ-5, while other isolates had only shown a mutant epitope (H38, Q40, I42, Y43 and K44) (Figure 5). It is suggested that mutation variants of N44 glycosylation site loss have great significance for development of PRRSV vaccines of enhanced protective efficacy. Three minimal epitopes (RLYRWR, EGHLIDLKRV and QWGRL) were precisely defined in the $C$ terminus of GP5 protein and were highly conserved among the North American type isolates [41]. The sequence "QWGRL" might be a characteristic of highly pathogenic PRRSV, while corresponding AA position of low pathogenic
PRRSV show "RWGRL" [41]. A mutation (R151G) of ST7 isolate was identical to MLV and BJ-4, while other six isolates were the same with VR2332, HUB2, CH-1a and HuN829 (Figure 5).

Phylogenetic analysis based on the deduced amino acid sequences of Nsp2 gene obtained during this study and those of isolates VR2332, and MLV strains retrieved from GenBank, indicated that all the seven Nsp2 sequences belonged to the North American genotype. Comparison between seven Chinese isolates and both VR-2332 MLV and BJ-4 showed 0.275-0.281, 0.2720.278 and $0.275-0.283$ nucleotide identity (Additional file 8), respectively. Remarkably, compared to the VR2332 and MLV strain, analysis of the partial Nsp2 sequences revealed that a 30-aa deletion of a fragment containing a major hydrophilic region had occurred from residues 540 to 569 (Figure 6), which was also previously reported $[42,43]$. Some evidences have pointed to the conclusion that the highly pathogenic PRRSV

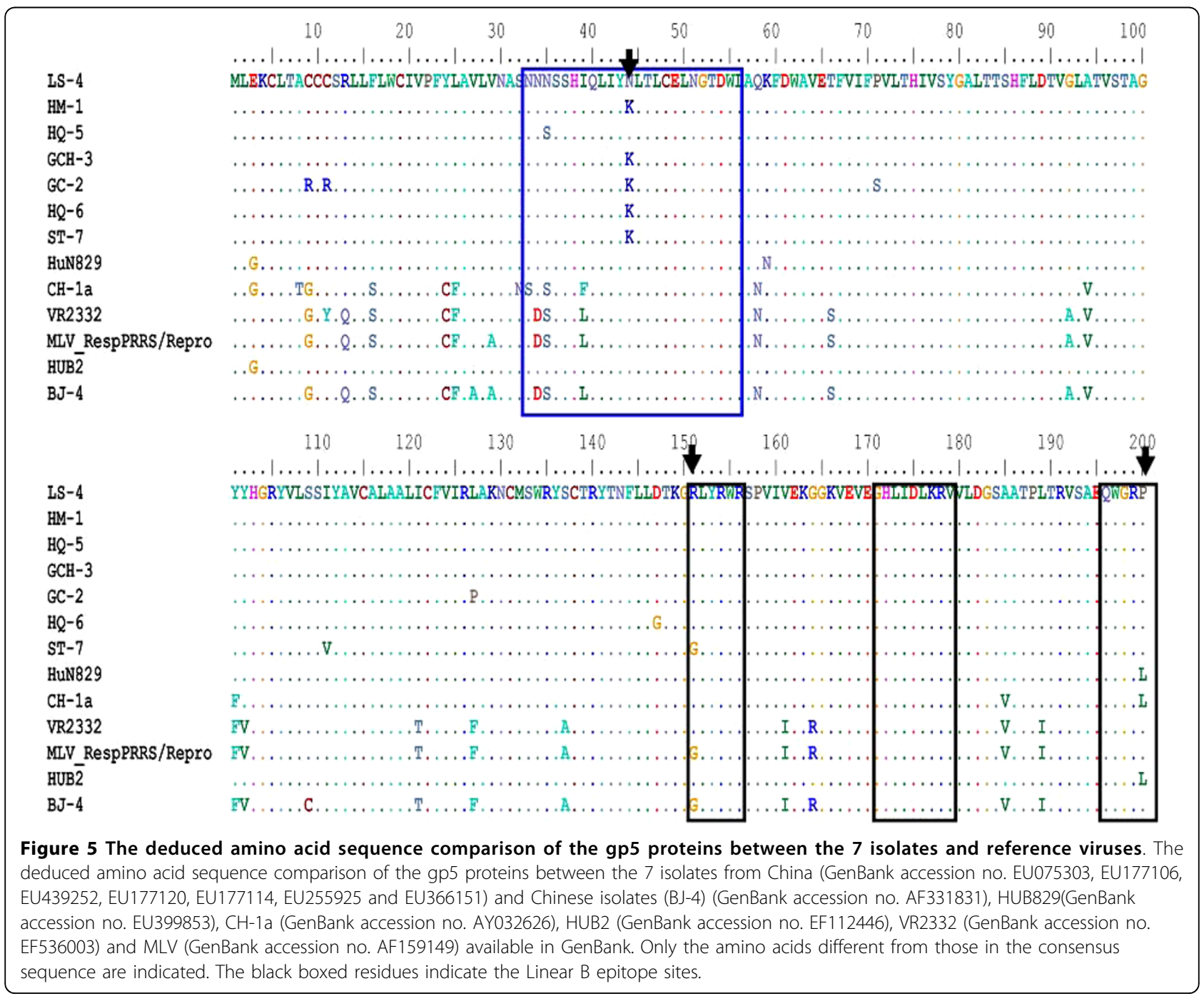




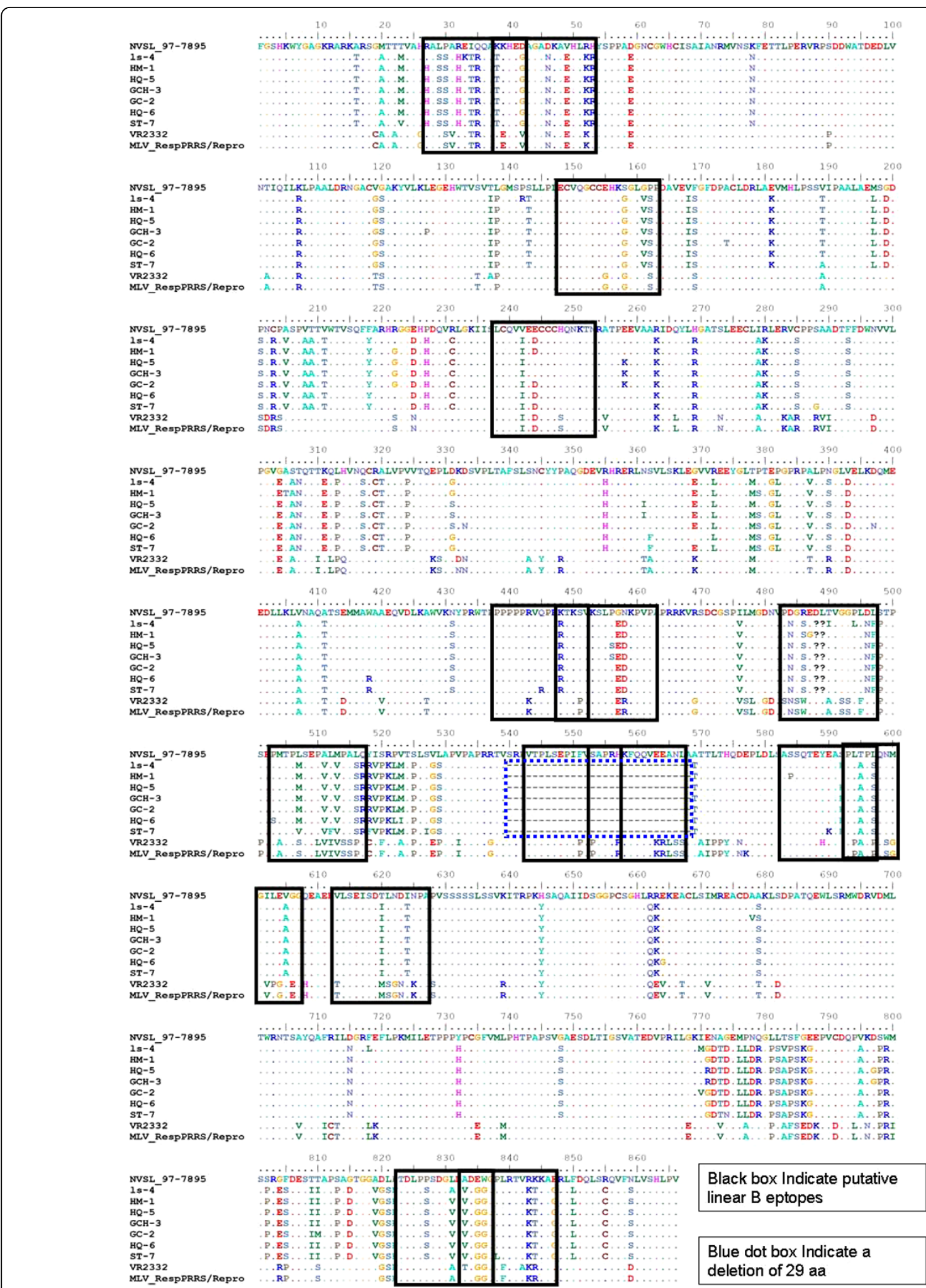

Figure 6 Amino acid sequence comparison of the nsp2 proteins between the 7 isolates from China (GenBank accession no. EU075304 EU177102, EU255920, EU669820, EU255919, EU653014 and EU642604) and another isolates NVSL 97-7895 (GenBank accession no. AY545985), VR2332 (GenBank accession no. EF536003) and MLV (GenBank accession no. AF159149) available in GenBank. Dots indicate amino acids identical to LS-4 and deletions are indicated by dashes (-). The black boxed residues indicate the putative linear B epitopes. The blue dot boxed indicate a deletion of AA. 
with the 30-aa deletion in Nsp2 is the causative agent of atypical PRRS in China $[42,44,45]$. On the contrary, another research has reported that the 30-amino-acid deletion in the Nsp2 of highly pathogenic porcine reproductive and respiratory syndrome virus emerging in China is not related to its virulence [46].

The Nsp2 protein has been shown to be highly variable among arteriviruses, with similarities observed only in the amino- and carboxy-terminal domains whereas the central region of the protein varies in both length and amino acid composition [47]. Interestingly, the Nsp2 protein was found to contain the highest frequency of immunogenic epitopes including positions 27-42, 37-52, 483-497, 503-517,823-837 and 833-847, when compared to reference virus strains examined in this study (Figure 6). In addition, these immuno-dominant B-cell epitopes were scattered along the protein sequence, and most of them were localized within predicted hydrophilic regions of the protein by predicting hydropathy Kyte-Doolittle method (Additional file 9). These results were not unexpected since hydrophilic amino acid sequences are likely to be exposed on the surface of the protein and thus may be more easily recognized by B-lymphocytes. A previous report has also demonstrated the occurrence of a cluster of B-cell epitopes in Nsp2 of an EUtype PRRSV isolate and a north America PRRSV isolate, NVSL 97-7895 strain [33,48].

\section{Conclusions}

In conclusion, this study presented detailed molecular and phylogenetic analyses for seven field isolates of PRRSV from China. The collected results revealed that the highly pathogenic PRRSV variants with the 30-aa deletion in Nsp2 were still the dominating viruses in China. The genetic diversity of PRRSV strain existed in the field in China. These results might be useful for the origin and genetic diversity of PRRSV Chinese isolates and the development of vaccine candidates in the future.

\section{Methods}

\section{Cell culture and viruses}

Swine Alveolar Macrophages (SAM) were obtained from about 4 week-old pigs as previously described [49]. The cells were cultured in RPMI-1640 medium supplemented with $10 \%$ fetal bovine serum and antibiotics $(25 \mathrm{U} / \mathrm{ml}$ penicillin, $25 \mu \mathrm{g} / \mathrm{ml}$ streptomycin, $40 \mu \mathrm{g} / \mathrm{ml}$ gentamicin, $25 \mu \mathrm{g} / \mathrm{ml}$ neomycin and $300 \mathrm{U} / \mathrm{ml}$ polymyxin). Monkey kidney cell line, MARC-145 [50], was cultured in Eagle's minimum essential medium supplemented with $5 \%$ fetal bovine serum. Infectious PRRSV, LS-4, HM-1, HQ-5, GCH-3, GC-2, HQ-6 and ST-7 strains from Shijiazhuang of Hebei province (Additional file 10), were isolated in our laboratory at National Center of Wildlife Born
Diseases, by inoculation of the sera or the tissue homogenates into SAM or MARC-145 cells.

\section{RNA extraction, reverse transcriptase PCR (RT-PCR) and nucleotide sequencing}

RNAs were extracted from $200 \mu \mathrm{l}$ of the culture supernatant of the PRRSV-infected SAM or MARC-145 cells using QIAamp viral RNA mini kit (Qiagen) according to the manufacturer's recommendation. Each target gene was amplified using QIAGEN $^{\circ}$ One-Step RT-PCR kit (Qiagen). PCR and sequencing primers were shown as Table 1 . The PCR reactions were done in a total volume of $25 \mu \mathrm{l}$ containing $1 \mathrm{ng}$ of the extracted cDNA,,200 $\mu \mathrm{M}$ of each (dNTP) (TakaRa), $1 \times$ PCR buffer (TakaRa), $3.0 \mathrm{mM} \mathrm{MgCl}$, and $2.5 \mathrm{U}$ of Taq polymerase(TakaRa). The PCR conditions were set as initial denaturation step at $94^{\circ} \mathrm{C}$ for $3 \mathrm{~min}$ followed by 40 cycles, each consisted of denaturation step at $94^{\circ} \mathrm{C}$ for $1 \mathrm{~min}$, annealing step at $55^{\circ} \mathrm{C}$ for $1 \mathrm{~min}$ and elongation step at $72^{\circ} \mathrm{C}$ for $2 \mathrm{~min}$, a final extensition at $72^{\circ} \mathrm{C}$ for $10 \mathrm{~min}$ was included. Size of amplicons was verified by agarose gel electrophoresis in TAE buffer using known standards. PCR products were purified using QIAquick $^{\circ}$ PCR purification kit (Qiagen) and submitted to Invitrogen for sequencing.

\section{Construction of phylogenetic trees}

Nucleotide BLASTn analysis http://www.ncbi.nlm.nih. gov/BLAST was used to identify related genes of the viruses, and the reference sequences were obtained from GenBank. Pair-wise sequence alignments were also performed with the MEGA4.0 program [51]http://www. megasoftware.net/ to determine nucleotide sequence similarities. Alignments of each virus sequence were generated using program ClustalW [52]http://clustalw. genome.ad.jp/. Phylogenetic analyses of the aligned sequences for 5 gene segments (ORF2-5 and NSP2) were performed by the neighbor-joining method with 1000 bootstraps and Maximum-Likelihood with

Table 1 Primers used for PCR amplification of ORF2ORF5 and NSP2 from PRRSV

\begin{tabular}{cc}
\hline Genes & Primer sequence \\
\hline ORF2 & 5'-ACGAAGCTTATGAAATGGGGTCTATG-3' \\
& 5'-TATCTCGAGTCACCGTGAGTCAAAAG-3' \\
ORF3 & 5'-TTCATGATTTCAGCAATGGCTAA-3' \\
& 5'-GATGGTGATGTACACGGGCGT-3' \\
ORF4 & 5'-ACGGCGGCAATTGGTTCACCTA-3' \\
& 5'-CGTGGTCAAGCATTTCCCCAACATA-3' \\
ORF5 & 5'-CCTGAGACCATGAGGTGGGG-3' \\
& 5'-TTAGGGCATATATCATCACTGG-3' \\
NSP2 & 5'-TGAYTGGRATGTTGTGCTYCCTGG-3' \\
& 5'-ATGCGAGARAGCCAYTCCTGCGT-3'
\end{tabular}


100 bootstraps by using PHYLIP version $3.67 \mathrm{http}: /$ evolution.gs.washington.edu/phylip.html. All gene accession number of the isolates and other references virus were shown as Additional file 11.

\section{Comparison and analysis of amino acid sequences in gp2, gp3, gp4, gp5 and nsp2}

Amino acid sequences of Chinese isolate virus (BJ-4), VR2332 and MLV gp2, gp3, gp4 and gp5 proteins were retrieved from the public domain database Entrez Protein, and compared each of them with all the 7 isolate virus proteins using the software ClustalW [52].

Additional file 1: Table S1: Estimates of Evolutionary Divergence between isolates and references based on gp 5 gene Sequences.

Additional file 2: Table S2: Estimates of Evolutionary Divergence between isolates and references based on gp2 gene Sequences.

Additional file 3: Figure S1: Antigenic index analysis: plots of ORF2 generated by the Kyte and Doolittle method. Major areas of difference are indicated by arrows. a, GC-2 was a representative of other two isolates because the same plots were shown for GC-2 and GCH-3. b, LS-4 was a representative of other two isolates because the same plots were shown for HM-1 and HQ-6. c, VR2332 was a representative of other three reference virus because the same plots were shown for BJ-4 and MLV.

Additional file 4: Table S3: Estimates of Evolutionary Divergence between isolates and references based on gp3 gene Sequence.

Additional file 5: Figure S2. Antigenic index analysis plots of ORF3 generated by the Kyte and Doolittle method. Major areas of difference are indicated by arrows. a, LS- 4 was a representative of other six isolates because the same plots were shown for GC-2, ST-7, $\mathrm{GCH}-3, \mathrm{HM}-1, \mathrm{HQ}-5, \mathrm{HQ}-6$ and LS-4. b, VR2332 was a representative of other three reference virus because the same plots were shown for BJ-4 and MLV.

Additional file 6: Table S4. Estimates of Evolutionary Divergence between isolates and references based on gp4 gene Sequences.

Additional file 7: Figure S3. antigenic index analysis: plots of ORF4 generated by the Kyte and Doolittle method. Major areas of difference are indicated by arrows. a, LS- 4 was a representative of other five isolates because of the same plots (GCH-3, HM-1, HQ-5, HQ-6 and ST-7). $b, B J-4$ was a representative of other two reference virus because the same plots were shown for BJ-4 and MLV.

Additional file 8: Table S5: Estimates of Evolutionary Divergence between isolates and references based on Nsp2 gene Sequences. Additional file 9: Table S6: prediction of immuno-dominant B-cell epitopes of NSP2 protein.

Additional file 10: Table S7: The information of seven isolates from pig farms of Shijiazhuang city, in Hebei province.

Additional file 11: Table S8: Summary of the PRRSV analyzed in this study.

\section{Acknowledgements}

This work was supported by grants from: Hi-Tech Research and development program of China (863, 2007AA100606), National Science and Technology Ministry(ID:2009BAl83B01) and The National Key Basic Research and Development Program of China $(973,2007 B C 109103)$.

\section{Author details}

${ }^{1}$ National Research Center for Wildlife Born Diseases, Institute of Zoology, Chinese Academy of Sciences, Beijing 100101, China. ${ }^{2}$ College of Life Science, Hebei Normal University, Shijiazhuang, Hebei, 050060 China.
${ }^{3}$ Department of Life Science, Heze College, Heze, Shandong Province 274015 China. ${ }^{4}$ Department of Zoology, Faculty of Science, Kafr El-Sheikh 33516 Egypt.

\section{Authors' contributions}

$\mathrm{HXH}$ and CMW conceived the project. JL and HMZ conducted cell culture and isolation of PRRSV. BW and SA conducted data analysis and construction of phylogenetic trees. YHG and GYD conducted RNA extraction, reverse transcriptase PCR (RT-PCR) and nucleotide sequencing. WCM, BHZ and $\mathrm{HHX}$ wrote the paper. All authors read and approved the final manuscript. The authors declare no conflict of interest.

Received: 28 February 2010 Accepted: 20 May 2010

Published: 20 May 2010

\section{References}

1. Albina E: Epidemiology of porcine reproductive and Respiratory syndrome (PRRS): an overview. Vet Microbiol 1997, 55:309-316.

2. Wensvoort G, Terpstra C, Pol JM, Ter Laak EA, Bloemraad M, De Kluyver EP. Mystery swine disease in The Netherlands: the isolation of Lelystad virus. Vet Q 1991, 13(3):121-130.

3. Cavanagh D: Nidovirales: a new order comprising Coronaviridae and Arteriviridae. Arch Virol 1997, 142(3):629-633.

4. Gao ZQ, Guo X, Yang HC: Genomic characterization of two Chinese isolates of porcine respiratory and reproductive syndrome virus. Arch Virol 2004, 149:1341-1351.

5. Stadejek T, Oleksiewicz MB, Potapchuk D, Podgorska K: Porcine reproductive and respiratory syndrome virus strains of exceptional diversity in eastern europe support the definition of new genetic subtypes. J Gen Virol 2006, 87:1835-1841.

6. An TQ, Zhou YJ, Liu GQ, Tian ZJ, Li J, Qiu HJ, Tong GZ: Genetic diversity and phylogenetic analysis of glycoprotein 5 of PRRSV isolates in Mainland China from 1996 to 2006: coexistence of two NAsubgenotypes with great diversity. Vet Microbiol 2007, 123:43-52.

7. Dea S, Gagnon CA, Mardassi H, Pirzadeh B, Rogan D: Current knowledge on the structural proteins of porcine reproductive and respiratory syndrome (PRRS) virus: comparison of the North American and European isolates. Arch Virol 2000, 145(4):659-688.

8. Wu WH, Fang Y, Farwell R, Steffen-Bien M, Rowland RR, ChristopherHennings J, Nelson EA: A 10-kDa structural protein of porcine reproductive and respiratory syndrome virus encoded by ORF $2 \mathrm{~b}$. Virology 2001, 287(1):183-191.

9. Labarque G, Van Reeth K, Nauwynck H, Drexler C, Van Gucht S, Pensaert M: Impact of genetic diversity of European-type porcine reproductive and respiratory syndrome virus strains on vaccine efficacy. Vaccine 2004, 22(31-32):4183-4190.

10. Meulenberg JJ: PRRSV, the virus. Vet Res 2000, 31(1):11-21.

11. Meulenberg JJ, Petersen-den BA, De Kluyver EP, Moormann RJ, Schaaper WM, Wensvoort G: Characterization of proteins encoded by ORFs 2 to 7 of Lelystad virus. Virology 1995, 206(1):155-163.

12. Snijder EJ, van Tol H, Pedersen KW, Raamsman MJ, de Vries AA: Identification of a novel structural protein of arteriviruses. J Virol 1999, 73(8):6335-6345

13. Nelson EA, Christopher-Hennings J, Drew T, Wensvoort G, Collins JE, Benfield DA: Differentiation of U.S. and European isolates of porcine reproductive and respiratory syndrome virus by monoclonal antibodies. J Clin Microbiol 1993, 31(12):3184-3189.

14. Mardassi H, Massie B, Dea S: Intracellular synthesis, processing, and transport of proteins encoded by ORFs 5 to 7 of porcine reproductive and respiratory syndrome virus. Virology 1996, 221(1):98-112.

15. Delputte PL, Vanderheijden N, Nauwynck HJ, Pensaert MB: Involvement of the matrix protein in attachment of porcine reproductive and respiratory syndrome virus to a heparin-like receptor on porcine alveolar macrophages. J Virol 2002, 76(9):4312-4320.

16. Chang CC, Yoon KJ, Zimmerman JJ, Harmon KM, Dixon PM, Dvorak CM, Murtaugh MP: Evolution of porcine reproductive and respiratory syndrome virus during sequential passages in pigs. J Virol 2002, 76(10):4750-4763.

17. Goldberg TL, Lowe JF, Milburn SM, Firkins LD: Quasispecies variation of porcine reproductive and respiratory syndrome virus during natural infection. Virology 2003, 317(2):197-207. 
18. VanWoensel PA, Liefkens K, Demaret S: Effect on viraemia of an American and a European serotype PRRSV vaccine after challenge with European wild-type strains of the virus. Vet Rec 1998, 142(9):510-512.

19. Yang HC, Huang FF, Guo X, Gao Y, Li H, Chen S: Sequencing of genome of porcine reproductive and respiratory syndrome virus isolate BJ-4. J Agric Biotechnol 2001, 9(3):212-218.

20. Halbur PG, Paul PS, Frey ML, Landgraf J, Eernisse K, Meng XJ, Lum MA Andrews JJ, Rathje JA: Comparison of the pathogenicity of two U.S. porcine reproductive and respiratory syndrome virus isolates with that of the Lelystad virus. Vet Pathol 1995, 34:648-660.

21. Halbur PG, Paul PS, Meng XJ, Lum MA, Andrews JJ, Rathje JA: Comparative pathogenicity of nine U.S. porcine reproductive and respiratory syndrome virus (PRRSV) isolates in a 5-week-old cesareanderivedcolostrum-deprived pig model. J Vet Diagn Investig 1996, 8:11-20.

22. Halbur PG, Paul PS, Frey ML, Landgraf J, Eernisse K, Meng XJ, Andrews JJ, Lum MA, Rathje JA: Comparison of the antigen distribution of two U.S. porcine reproductive and respiratory syndrome virus isolates with that of the Lelystad virus. Vet Pathol 1996, 33:159-170.

23. Mengeling WL, Lager KM, Vorwald AC: Clinical consequences of exposing pregnant gilts to strains of porcine reproductive and respiratory syndrome (PRRS) virus isolated from field cases of "atypical" PRRS. Am J Vet Res 1998, 59:1540-1544

24. Meng XJ, Paul PS, Halbur PG: Molecular cloning and nucleotide sequencing of the 3 '-terminal genomic RNA of porcine reproductive and respiratory syndrome virus. J Gen Virol 1994, 75:1795-1801.

25. Meng XJ, Paul PS, Morozov I, Halbur PG: A nested set of six or seven subgenomic mRNAs is formed in cells infected with different isolates of porcine reproductive and respiratory syndrome virus. J Gen Virol 1996, 77:1265-1270.

26. Key KF, Haqshenas G, Guenette DK, Swenson SL, Toth TE, Meng XJ: Genetic variation and phylogenetic analyses of the ORF5 gene of acute porcine reproductive and respiratory syndrome virus isolates. Vet Microbio/ 2001, 83:249-263.

27. Meng XJ: Heterogeneity of porcine reproductive and respiratory syndrome virus: implications for current vaccine efficacy and future vaccine development. Vet Microbio/ 2000, 74:309-329.

28. Torrison $J$, Knoll M, Wiseman B: Evidence of pig-to-pig transmission of a modified live vaccine. Proceedings of the 27th Annual Meeting of the American Association of Swine Practitioners, Nashville, Tenn. American Society of Swine Veterinarians, Perry, lowa 1996, 89-91.

29. Zhou L, Chen SX, Zhang JL, Zeng JW, Guo X, Ge XN, Zhang DB, Yang HC: Molecular variation analysis of porcine reproductive and respiratory syndrome virus in China. Virus Res 2009, 145(1):97-105.

30. Tian KG, Yu XL, Zhao TZ, Feng YJ, Cao Z1, Wang CB, Hu Y, Chen XZ, Hu DM, Tian XS, Liu D, Zhang S, Deng XY, Ding YQ, Yang L, Zhang YX, Xiao HX, Qiao MM, Wang B, Hou LL, Wang XY, Yang XY, Kang LP, Sun M, Jin P, Wang SJ, Kitamura Y, Yan JH, Gao GF: Emergence of fatal PRRSV variants: unparalleled outbreaks of atypical PRRS in China and molecular dissection of the unique hallmark. PLOS ONE 2007, 2:e526.

31. Feng YJ, Zhao TZ, Nguyen T, Inui K, Ma Y, Nguyen TH, Nguyen VC, Liu D, Bui QA, Thanh TL, Wang CB, Tian KG, Gao GF: Porcine respiratory and reproductive syndrome virus variants, Vietnam and China, 2007. Emerg Infect Dis 2008, 14:1774-1776.

32. Snijder EJ, Meulenberg JM: Arteriviruses in Fields Virology. LippincottWilliams and Wilkins, PhiladelphiaKniper D, et al , 4 2001, 1:1205-1220.

33. Marcelo de L, Asit KP, Eduardo FF, Fernando AO: Serologic marker candidates identified among B-cell linear epitopes of Nsp2 and structural proteins of a North American strain of porcine reproductive and respiratory syndrome virus. Virology 2006, 353:410-421.

34. Zhou YJ, An TQ, He YX, Liu JX, Qiu HJ, Wang YF, Tong G: Antigenic structure analysis of glycosylated protein 3 of porcine reproductive and respiratory syndrome virus. Virus Res 2006, 118:98-104.

35. Meulenberg JJ, van Nieuwstadt AP, van Essen-Zandbergen A, Langeveld JP: Posttranslational processing and identification of a neutralization domain of the GP4 protein encoded by ORF4 of Lelystad virus. J Virol 1997, 71(8):6061-6067.

36. Mardassi H, Mounir S, Dea S: Molecular analysis of the ORF3-7 of porcine reproductive and respiratory syndrome virus, Quebec reference strain. Arch Virol 1995, 140:1405-1418.
37. Israrul HA, Byungjoon K, Fernando AO, Asit KP: Influence of N-Linked Glycosylation of Porcine Reproductive and Respiratory Syndrome Virus GP5 on Virus Infectivity, Antigenicity, and Ability To Induce Neutralizing Antibodies. J Virol 2006, 80(8):3994-4004.

38. Plagemann PGW, Rowland RRR, Faaberg KS: The primary neutralization epitope of porcine respiratory and reproductive syndrome virus strain VR-2332 is located in the middle of the GP5 ectodomain. Arch Virol 2002, 147:2337-2347.

39. Wissink EH, Kroese MV, Maneschijn-Bonsing JG, Meulenberg JJ, van Rijn PA, Rijsewijk FA, Rottier PJ: Significance of the oligosaccharides of the porcine reproductive and respiratory syndrome virus glycoproteins GP2a and GP5 for infectious virus production. J Gen Virol 2004, 85:3715-3723.

40. Oleksiewicz MB, Botner A, Normann P: Porcine B-cells recognize epitopes that are conserved between the structural proteins of American- and European-type porcine reproductive and respiratory syndrome virus. J Gen Virol 2002, 83(6):1407-1418.

41. Zhou YJ, Yu H, Tian ZJ, Liu JX, An TQ, Peng JM: Monoclonal antibodies and conserved antigenic epitopes in the $\mathrm{C}$ terminus of GP5 protein of the North American type porcine reproductive and respiratory syndrome virus. Vet Microbiol 2009, 138(1-2):1-10.

42. Li Y, Wang $X$, Bo K, Tang B, Yang B, Jiang W, Jiang P: Emergence of a highly pathogenic porcine reproductive and respiratory syndrome virus in the Mid-Eastern region of China. Vet J 2007, 174:577-584.

43. Hu HX, Li XL, Zhang ZF, Shuai JB, Chen N, Liu GQ, Fang WH: Porcine reproductive and respiratory syndrome viruses predominant in southeastern China from 2004 to 2007 were from a common source and underwent further divergence. Arch Virol 2009, 154:391-398.

44. LV J, Zhan JW, Sun Z, Liu WQ, Yuan SS: An infectious CDNA clone of a highly pathogenic porcine reproductive and respiratory syndrome virus variant associated with porcine high fever syndrome. J Gen Virol 2008, 89:2075-2079.

45. Zhou YJ, Hao XF, Tian ZJ, Tong GZ, Yoo D, An TQ: Highly virulent porcine reproductive and respiratory syndrome virus emerged in China. Trans Emerg Dis 2008, 55:152-164.

46. Zhou L, Zhang J, Zeng J, Yin S, Li Y, Zheng L: The 30-amino-acid deletion in the Nsp2 of highly pathogenic porcine reproductive and respiratory syndrome virus emerging in China is not related to its virulence. J Virol 2009, 83:5156-5167.

47. Allende R, Lewis TL, Lu Z, Rock DL, Kutish GF, Ali A, Doster AR, Osorio FA: North American and European porcine reproductive and respiratory syndrome viruses differ in non-structural protein coding regions. J Gen Virol 1999, 80(2):307-315.

48. Oleksiewicz MB, Botner A, Toft P, Normann P, Storgaard T: Epitope mapping porcine reproductive and respiratory syndrome virus by phage display: the nsp2 fragment of the replicase polyprotein contains a cluster of B-cell epitopes. J Virol 2001, 75(7):3277-3290.

49. Mengeling $W L$, Lager KM, Vorwald AC: Diagnosis of porcine reproductive and respiratory syndrome. J Vet Diagn Invest 1995, 7(1):3-16.

50. Kim HS, Kwang J, Yoon IJ, Joo HS, Frey ML: Enhanced replication of porcine reproductive and respiratory syndrome (PRRS) virus in a homogeneous subpopulation of MA-104 cell line. Arch Virol 1993, 133(3-4):477-483.

51. Kumar S, Tamura K, Jakobsen IB: MEGA2: Molecular evolutionary genetics analysis software. Bioinformatics 2001, 17:1244-1245.

52. Thompson JD, Higgins DG, Gibson TJ: CLUSTAL W: Improving the sensitivity of progressive multiple sequence alignment through sequence weighting, position-specific gap penalties and weight matrix choice. Nucleic Acids Res 1994, 22:4673-4680.

doi:10.1186/1471-2180-10-146

Cite this article as: Wang et al:: Phylogenetic analysis and molecular characteristics of seven variant Chinese field isolates of PRRSV. BMC Microbiology 2010 10:146. 